Abstract word count: 315

Text word count: 3,344

\title{
Do We Need Education on Right-to-Die Issues? \\ Medical Perspectives from Australia.
}

Diego De Leo*, Jacinta Hawgood, Naoko Ide

\author{
Australian Institute for Suicide Research and Prevention \\ World Health Organization Collaborating Centre \\ for Research and Training in Suicide Prevention
}

*Correspondence:

Prof. Diego De Leo, DSc, MD, PhD, FRANZCP,

AISRAP, Griffith University, Mt Gravatt Campus, QLD 4122, Australia

d.deleo@griffith.edu.au 


\section{Abstract}

Background: An increasing demand for physicians' involvement in life-ending decisions has led to extensive debate on euthanasia and right to die issues by social, political and medical groups. By definition, suicide prevention experts are considered to be pre-judgmentally biased on these aspects. However, their knowledge of the fields could actually make them important interlocutors in the debate. Aim: As a part of Commonwealth Department of Health and Aged Care's commission, an evaluation of the need for educating undergraduate medical students on suicide prevention, euthanasia and life-ending issues was performed. Methods: In Australia, semistructured interviews were conducted on samples of medical schools coordinators, medical students, and general practitioners (GPs). Specifically, key academics in Curriculum and /or Accreditation Committees from 10 out of 15 Australian Medical Schools (AMS) participated in a survey on the possible implementation of suicide prevention, euthanasia and life-ending issues in undergraduate courses. University of Queensland medical students $(n=373)$ were asked to rate their attitude toward the same issues. Twenty four GPs from 6 different states (rural/urban environments) were asked to rate the level of importance of a specific curriculum on suicide prevention, euthanasia and life-ending issues. Results: Suicide prevention education was perceived of critical importance by all. Medical students showed high interest in learning about euthanasia and life-ending issues (76.8\%), quality of life and quality of death $(85.1 \%)$, and different types of euthanasia and physician assisted suicide (70\%). They reported that physicians should be involved in ending-life decisions (89\%). Forty per cent of AMS thought education on euthanasia and life-ending issues was essential. Fifty four per cent of GPs considered education in euthanasia and related 
issues as a high priority. Conclusions: The increasing aging population and the high prevalence of chronic illness call for a growing involvement of physicians in this difficult area of medical practice. Globally, the need for undergraduate education on these matters is perceived as important and urgent.

Key Words: end of life, euthanasia, assisted suicide, suicide prevention, medical curriculum, general practitioner 


\section{Introduction}

There are rapidly increasing demands on physicians involved in life-ending decisions (LED), including euthanasia or physician-assisted suicide (EAS) (Marcoux et al, 2005). This is largely due to a steady increase in aging population and the high prevalence of chronic illnesses (Australian Institute of Health and Welfare, 2004). Euthanasia is defined as "the administration of drugs with the explicit intention of ending the patient's life, at the patient's request"; physician-assisted suicide is defined as "the prescription or supplying of drugs with the explicit intention of enabling the patient to end his or her life" (Goldney, 2001, p. 172). Participating in discussions about LED with terminally ill patients, as well as dealing with patients' requests for EAS, is emotionally and ethically challenging for medical practitioners (Haverkate et al., 2001; Stevens, 2006).

Today, education providing knowledge and skills to effectively deal with EAS and other life-ending-issues, such as withholding of treatments and administering lethal doses of opioids for patients' pain control, has become ever more important for undergraduate medical students for their future medical practice (Rapport \& Witzke, 1993; Hayes et al., 1999; Sullivan et al, 2003). There has been growing public support of legalisation of euthanasia and physician assisted suicide reported internationally, such as in various European countries including Belgium, Italy, Spain and Sweden (Cohen et al., 2006), and the United States (Duncan \& Parmelee, 2004). Furthermore, the few countries in which EAS is already legal have demonstrated an increasing trend in EAS practice. For example, in the Netherlands, EAS deaths rates reported by the Dutch Government showed that in 1990 there was a total of 2,405 
deaths, 3,252 in 1995, and 3,682 in 2001. On average, the number of euthanasia requests was approximately three times higher than those eventually accepted (Netherlands Institute for Health and Research, 2003). Onwuteaka-Philipsen et al (2003) estimated that EAS accounted for $1.7 \%$ of all deaths in Netherlands in 1990, $2.4 \%$ in 1995 and $2.6 \%$ in 2001. In Oregon, the figure of EAS deaths observed was much lower than in the Netherlands: 27 Oregonians died by ingesting the prescribed lethal medication (barbiturates) in 1999, 27 in 2001, 42 in 2003, 37 in 2004 and 32 in 2005, while approximately an equal number of requests was rejected every year (ODHS, 2006). In 2004, cases of physician-assisted suicide were 37, out of a total number of 30,332 deaths, thus corresponding to $0.01 \%$ (ODHS, 2006). Several explanations may be suggested for these considerable differences between the two countries. Firstly, the Netherlands have been practicing EAS since the 1980s; thus public and medical attitudes towards EAS are more 'settled' and established than in Oregon. Secondly, the rules associated with EAS practice are also different. Both Netherlands and Oregon EAS Acts require the patient's medical condition to be terminal, with the patient unbearably suffering; and, the patient's request has to be voluntary, after full knowledge of prognosis and future possibilities of palliative care (Netherlands Institute for Health Service Research, 2003; ODHS, 2006). However, the Oregon Acts have additional safeguards, which consist of two verbal requests formulated 15 days from each other, and a written request signed in the presence of two witnesses. In case of suspected psychiatric disorder or significant emotional alteration, the patient has to undergo a visit by a psychiatrist (ODHS, 2006).

In Australia, EAS was only legal in the Northern Territory between July 1996 and May 1997. Under the Act, seven terminally ill cancer patients requested physician- 
assisted suicide; of those, four people died (Kissane et al, 1998). Since the repeal of the Act in 1997, EAS is illegal in Australia. However, this does not stop physicians from being involved in ending-life-decisions (Khuse et al, 1997; Onwuteaka-Philipsen et al, 2006). Douglas and colleagues (2001) investigated medical practitioners involvement in ending-life decisions by administering self-completed surveys to randomly selected surgeons $(n=638$, with $68.9 \%$ response rate). Results indicated that 187 participants had received non-explicit/ambiguous EAS requests from cognitively competent patients, with 29 physicians administering lethal doses of drugs. Furthermore, 70 doctors received explicit EAS requests; 13 physicians accepted such requests. Douglas et al. (2001) estimated that within the general Australian doctor population between 32.6 and $39.9 \%$ of doctors use lethal drug administration to relieve patient pain, with up to $30.9 \%$ of doctors experiencing nonexplicit/ambiguous EAS requests, and up to $13 \%$ facing explicit EAS requests. In the United States, a slightly higher rate of EAS requests (20\%) was reported by a national sample of neurologists (Carver et al., 1999). It is important to mention here that results from these two studies might be subject to underestimations: in fact, both in the United States (with the exception of Oregon), and Australia EAS is illegal, thus medical doctors involved in this practice may have been reluctant to participate or report on the topic.

Nevertheless, these data indicate that practice of EAS and medical practitioners' involvement in life-ending decisions has become an important part of medical practice. There are several studies that have investigated the practice of EAS and the prevalence of suicidal ideation and risk factors associated with EAS. However, many of these studies suffer from methodological limitations such as, small sample size of 
terminally ill patients (Mak \& Elwyn, 2005) and a focus primarily on older populations (Lavery et al, 2001). One possible exception is represented by the research from Ganzini and colleagues (2000), who investigated risk factors for EAS requests in terminally ill subjects among 2,649 randomly selected physicians in Oregon. Of those, 144 had received a total of 211 requests for lethal prescriptions. Based on physicians' reports, over $50 \%$ of patients who requested EAS expressed loss of independence, poor quality of life, feeling ready to die and wanting to control own circumstances. Forty three per cent expressed physical pain as the main reason for EAS. In another study, Chochinov et al. (1995) interviewed 200 terminally ill patients in Canada. They found that moderate or severe pain was present in $76.5 \%$ of patients wishing to die. Additionally, a strong relationship between desire for death and depression existed (58\% of the patients). This evidence was also detected in a number of other studies (Emanuel et al, 2000; Kelly et al, 2003a, 2004; Marcoux et al, 2005; Rurup et al, 2005; Tieran et al, 2002). Loss of dignity and fear of becoming a burden for family were often reported as a reason for requesting EAS (Emanuel et al, 2000; Ganzini et al, 2000; Lavery et al, 2001; Mak \& Elwyn, 2005). These findings are important from a suicide prevention perspective, since the identified emotional conditions can be effectively treated (Hendin \& Klerman, 1993).

Considering these aforementioned risk factors for 'wish to die' among terminally ill patients, it would be desirable for physicians to be able to detect such patients and provide appropriate interventions (Raue et al, 2007). The need for education of physicians in end of life issues should include the provision of knowledge and skills to effectively deal with EAS and other life-ending-issues (Rapport \& Witzke, 1993; Hayes et al., 1999; Sullivan et al, 2003). Another important focus for education 
regards physician's ability to deal with the emotional impacts of life-ending decisions of terminally ill patients (Haverkate et al, 2001; Kelly et al., 2003b; Kelly, Varghese \& Pelusi, 2003; Stevens, 2006). It has been reported that physicians who care for terminally ill patients experience a limited ability to provide for patients' emotional needs (Kelly, Varghese, Pelusi, 2003). Furthermore, physicians who participate in EAS practices can feel overcharged with responsibilities (Haverkate et al, 2001).

This study investigates the need for education in euthanasia and other life-ending issues among undergraduate medical students, medical schools and general practitioners. It was hypothesised that all three groups would show different viewpoints and levels of interest in the education of EAS and other life-ending-issues. The study was conducted in Australia between April and June, 2006, as part of a large investigation commissioned by the Commonwealth Department of Health and Aging, in order to evaluate the needs for a suicide prevention curriculum in undergraduate medical students (Hawgood et al, 2006; 2008). 


\section{Methodology}

\section{Undergraduate Medical School Students}

Study participants were from first to fourth year undergraduate medical students of the University of Queensland (UQ). Although UQ was selected as a matter of convenience (in terms of closeness with the investigating team), UQ students were not dissimilar from other Australian Universities in terms of gender, age and ethnicity. However, the state of Queensland is traditionally exposed to higher rates of suicide (approximately 20\%) than the national average (De Leo \& Heller, 2004).

Two measures, "Attitude towards Suicide Prevention" and "Attitude towards Euthanasia and Life-Ending Decisions", were used. These measures were delivered as part of the main survey which investigated students' needs, perspectives, reactions, attitudes, and thoughts on suicide prevention curricula (reported in Hawgood et al, 2006). The whole survey was composed of selfadministered questionnaires and required approximately 15 to 20 minutes to complete.

With the permission of the medical school, the investigators were allowed to access to lectures (first and second year students) and tutorials (third and fourth year students) with the largest number of students. The survey was administered at the end of lectures or tutorial groups. The investigators had the opportunity to administer one survey per year grade. 
1) Attitudes toward Suicide Prevention. Students' attitudes towards suicide prevention were investigated by using the Attitudes toward Suicide Prevention (ASP) Scale (Herron et al, 2001). The measure consisted of 14 items with a 5point Likert scale response option (items listed in Results section). The ASP Scale has a good test-retest reliability $(\mathrm{r}=.85)$, and reported adequate internal reliability (Cronbach's alpha $=.77)($ Herron et al, 2001).

2) Attitude towards Euthanasia and LED and Attitude towards physician's involvement in LED. The measure consisted of five questions asking students' attitudes toward leaning about the right to die issue, desire to be taught about different types of euthanasia and assisted suicide, exploring concepts such as 'quality of life' and 'quality of death', medical professionals' involvement in endof-life issue discussion, and medical professionals' involvement in life-ending decisions. Participants were asked to rate their level of agreement by using the 5point Likert-type scale (Strongly Agree, Agree, Neither Agree nor Disagree, Disagree, Strongly Disagree).

\section{Australian Medical Schools}

The investigators approached all 15 medical schools in Australia via phone calls and formal e-mails. Appropriate participants were identified for each AMS through the faculty administration or executive secretaries to the Dean or Head of each Medical Faculty. These participants were administered a semi-structured telephone interview (taking 30 to 40 minutes) on existing curricula, needs and perspectives on suicide prevention and life-ending issues. Specifically, one of the 
questions concerned the priority of specific content areas of suicide prevention (including euthanasia and other life-ending issues) in a new educational curriculum. Representatives of the medical schools were asked to rate their views on priority levels using a 5-point Likert scale (from very low to very high) for nine specific areas of training (for a complete examination of materials, a copy of Hawgood et al's report can be obtained from the Commonwealth of Australia).

\section{Medical doctors}

Medical doctors (MD) were self-selected subjects recruited through advertisements placed in newsletters disseminated by the Australian Division of General Practice and the State Division of General Practice, as well as State Branches of the Australian Medical Association. The investigators planned to obtain the collaboration of four physicians from each state (two from urban and two from rural areas). Participants were offered a $\$ 60$ reimbursement for their time to participate in the study.

As in the case of medical faculties and schools, doctors were asked to rate their views on priority levels indicated by a 5-point Likert type scale for the same nine areas of training.

Recruited medical doctors participated in the study via semi-structured telephone interviews or self-reported survey (with the same content as the semi-structured interview). 


\section{Ethics Approval}

Ethics approval for the three branches of the study was approved by the Griffith University Ethics Committee, which subsequently accelerated the approval process by the University of Queensland Ethics Committee.

\section{Results}

\section{Undergraduate Medical Students}

A total of 373 students completed the survey, resulting in an average response rate of $81.5 \%$. Table 1 presents participants' gender and mean age characteristics by year. Participant numbers for $3^{\text {rd }}$ and $4^{\text {th }}$ year students were considerably lower compared to first and second year student numbers.

[Please insert Table 1 here]

In general, results indicated a positive attitude towards suicide prevention (Table 2). The one item that showed student's less positive attitudes was, 'Working with suicidal patients is not rewarding' (approximately 60\% reported as 'uncertain' and $30 \%$ 'disagree'). Furthermore, the item stating, 'It is easy for people not involved in clinical practice to make judgements about suicide prevention' received the largest number of agreement from students (46\%), while $33 \%$ of students were uncertain about the statement $(9.9 \%$ strongly agree, $6.7 \%$ disagree and $1.6 \%$ strongly disagree). There were varied responses for 'People have the right to take their own life'. Approximately $37 \%$ of students were uncertain with the 
statement, while $24 \%$ agreed, $6 \%$ strongly agreed, $15.5 \%$ disagreed and $14 \%$ strongly disagreed.

[Please insert Table 2 here]

A high proportion of students were interested in education topics such as 'quality of life and quality of death' (85.1\%), 'euthanasia and 'right-to-die issue' (76.8\%), and 'different types of euthanasia and physician assisted suicide' (66.9\%) (Figure1). The idea of physicians' involvement in discussions regarding 'end-oflife issues' was highly supported by students (88.8\%). Interestingly, circa $50 \%$ of students agreed that physicians' should actively participate in life-ending decisions, although 29\% did not agree or disagree, and 15\% disagreed (Figure 2).

[Please insert Figure 1 here]

[Please insert Figure 2 here]

\section{Australian Medical Schools (AMS)}

A total of 10 out of 15 AMS agreed to participate in the study (71\% response rate), consisting of four universities from Queensland, two from South Australia, two from Victoria, one from ACT, and one from Western Australia. Participants involved in the study were the school representatives who were key academics in Curriculum and/or Accreditation Committees with AMS.

Two AMS rated Euthanasia and Other Life-Ending Issues in education as 'very high priority', 4 AMS rated theses issues as 'high priority', and 4 AMS rated them 
as 'average priority'. This indicates that $60 \%$ of AMS perceived such education to be more than an average priority. The highest priority area in suicide prevention was 'suicide risk assessment' (90\%), and 'intervention and treatment strategies' (90\%). Areas such as 'referral systems' (80\%) and 'self-management with related stress' $(80 \%)$ were also rated as relatively high priority, followed by 'legal issues and duty of care' (70\%), 'euthanasia and other life-ending-issues' (60\%), 'monitoring and follow-up processes' (60\%), 'bereavement and postvention' (40\%), and 'population-level intervention strategies' (40\%) (Figure. $3)$.

[Please insert Figure 3 here]

None of the nine areas in suicide prevention was rated as 'not relevant'. Forty per cent of AMS rated 'Euthanasia and Other Life-Ending Issues' to be an essential learning outcome, while $60 \%$ reported it to be a 'desirable' outcome. 


\section{Medical Doctors}

Medical doctors were 24 Australian general practitioners (GPs) from both rural and urban areas. Five GPs were from Queensland, 5 from Victoria, 4 from South Australia, 3 from Western Australia, 2 from the Northern Territory, and 1 was from New South Wales. Four GPs wanted to remain anonymous and their location remained unidentified; 10 GPs were from rural areas, and 10 GPs from urban areas,

Specific areas were identified as being a priority for inclusion in a future undergraduate medical program. The areas of greatest priority were: suicide risk assessment (100\%) and intervention and treatment strategies (100\%), followed by understanding principles of suicide risk and self-harm (95.8\%), and selfmanagement and dealing with related stress $(91.7 \%)$. Other areas rated as of priority for inclusion were: bereavement and post-treatment (87.5\%), management strategies (83.3\%), legal issues and duty of care (87.5\%), referral systems (75\%), monitoring and follow-up processes (75\%), population-level strategies (62.5\%), and euthanasia and other ending-life issues (54.2\%). Although Euthanasia and Other Life-Ending-Issues received the lowest scores compared to other SP areas, 9 GPs rated it as a very high priority, 4 rated it as high priority, 9 considered it as an average priority, and 1 rated it as low priority. 


\section{Discussion}

This study presented a preliminary investigation that (only) descriptively looked at perceived needs of 'Euthanasia and Other Life-Ending-Issue Education' from the perspectives of AMS, GPs and undergraduate medical students in Australia. Overall, all three groups presented a high interest in euthanasia and other life-ending issues education for inclusion in medical curricula. AMS considered education in euthanasia and other related issues to be a high priority, and stated that such education has to be an essential learning outcome for undergraduate medical students. More than half of GPs also thought such education to be a high priority.

As expected, the majority of medical students were interested in learning about 'quality of life and quality of death', 'euthanasia and right-to-die issue 'and 'different types of euthanasia and physicians assisted suicide'. These results indicate that medical students are likely to be aware of the importance of acquiring knowledge and skills in euthanasia and other life-ending issues for their future medical career. Although almost $90 \%$ of students believe that physicians should be involved in discussion about end-of-life issues, their views on physicians' actual involvement in life-ending decisions varied greatly. While half of the participants agreed, a third of them did not agree or disagree, and the rest disagreed. Similarly, half of the participants agreed with the statement 'It is easy for people not involved in clinical practice to make judgement about suicide prevention', while one third of the participants were uncertain about the statement. Schwartz et al. (2005) reported that students who received end-of-life education showed less concern regarding working with dying patients than those without such education. These findings can be applied 
to our results, even though our question was specifically targeting those involved in life-ending decision-making processes and suicide prevention. Of course, the individual variability of views about right-to-die issues could have been influenced by students' own ethical, moral and religious standings (De Leo \& Hawgood, 2008). As Hayes et al. (1999) noted, it is important for medical students to receive an education that provides guidelines for medical ethics, facilitates students' self-awareness of their own personal values, and provides skills to manage conflicts between their own beliefs and public opinion.

\section{Limitations}

Time constraints directly impacted on participant recruitment process in all three groups. The present study was a part of the large pilot study investigating the need for suicide prevention education in undergraduate medical students and was commissioned by the Commonwealth of Australia, Department of Health and Aging. In the case of medical students, only one administration of the survey per year grade was allowed, due to the time limits. Most probably, this justifies the small number of third and fourth year participants. However, characteristics of UQ medical students are not considered to be dissimilar from other medical students in Australia, thus the results should be quite representative of the general population of medical students. Time constraints also impacted on GPs recruitment, which ended by being not equally representative of the eight States and Territories of Australia. In addition, the choice of GPs could be in itself a source of criticism (for example, why not to choose geriatricians or oncologists?). However, we took this decision on the basis of the vast literature underscoring the fact that people contemplating suicidal behaviour often visit their GPs prior to their fatal act (Luoma et al, 2002; Marquet et al, 2005; Scoullar 
$\&$ Smith, 2002). GPs may not be the best possible group to investigate about the need for education in ending-life issues; hospital physicians such as anaesthetists, neurologists, and oncologists may be more frequently in contact with those themes (Onwuteaka-Philipsen et al., 2006). However, increasing home care for terminally ill patients is also destined to involve the presence of a growing number of family physicians (Commonwealth Department of Health and Aged Care, 2002).

\section{Conclusions}

The present study indicated that in the medical 'world', particularly in undergraduate medical students, there is a high need for education in both suicide prevention (Hawgood et al, 2008) and euthanasia and other life-ending issues. On a global level, physicians are expected to face increasing demands to be involved in these challenging themes. Therefore, it would be important for physicians to be well equipped both culturally and emotionally, and be able to manage difficult decisionmaking processes without endangering their own wellbeing. Developing effective medical training education in right-to-die issues would require deep knowledge. Not many experts are currently available to provide such education. Possibly, suicide prevention professionals could be called to provide their expertise, temporarily supplying for those specificities that are embedded with euthanasia and assisted suicide themes.

\section{Conflict of interest}

None 


\section{Acknowledgements}

The authors wish to acknowledge the School of Medicine of the University of Queensland, and the Queensland Skills Development Centre, Queensland Health, who participated in as research investigators in this study. Specific thanks must also go the Australian Medical Schools and the General Practitioners and the undergraduate Medical Students of the University of Queensland who participated in this study.

This study was funded by the Australian Government Department of Health and Ageing as a part of Australia's National Suicide Prevention Strategy (NSPS, 2002006). The funding body did not have a role in the data collection, analysis or interpretation of results or in the composition of this paper. 


\section{References}

Australian Institute of Health and Welfare (2004). Australia's Health. Australian Government, Canberra.

Carver, A.C., Vickrey, B.C., Bernat, J.L., Keran, C., Ringle, S.P., Foley, K.M. (1999). End-of-life care: a survey of US neurologists' attitudes, behaviour, and knowledge. Neurology, 53, 284-293.

Chochinov, H.M., Wilson, K.G., Murray, E., Neil, M, et al. (1995). Desire for death in the terminally ill. American Journal of Psychiatry, 125 (8), 1185-1191.

Cohen, J., Marcoux, I., Bilsen, J., Deboosere, P., van der Wal, G., Deliens, L. (2006). Trends in acceptance of euthanasia among general European Countries (1981-1999). European Journal of Public Health, 16, 663-669.

Commonwealth Department of Health and Aged Care (2002). National Palliative care strategy: National framework for palliative care service development. Commonwealth of Australia, Canberra.

De Leo, D., Heller, T. (2004) Who are the kids who self-harm? An Australian selfreport school survey. Medical Journal of Australia, 181, 140-144, 2004.

De Leo, D., Hawgood, J.L. (2008) Impact of specialty on attitudes of Australian medical practitioners to end-of-life decisions. Medical Journal of Australia, 189, 34950, 2008.

Douglas, C.D., Kerridge, I.H., Rainbird, K.J., McPhee, J.R., Hancock, L., Spigelman, A.D. (2001).The intention to hasten death: a survey of attitudes and practices of surgeons in Australia. Medical Journal of Australia, 175, 511-515.

Duncan, O.D., Parmelee, L.F.(2004). Trends in public approval of euthanasia and suicide in the US, 1947-2003. Journal of Medical Ethics, 32, 266-272.

Emmanuel, E.J., Fairclough, D.L., Emanuel, L.L. (2000). Attitude and desire related to euthanasia and physician-assisted suicide among terminally ill patients and their care givers. Journal of American Medical Association, 284, 2460-2468.

Ganzini, L., Nelson, H.D., Schmidt, T.A., Kraemer, D.F, et al. (2000). Physicians' experience with the Oregon Death with Dignity Act. New England Journal of Medicine, 342, 557-564.

Goldney, R. (2001). Euthanasia: The Australian experience. D. De Leo (Ed). Suicide and Euthanasia in Older Adults. Seattle: Hogrefe \& Huber Publisher.

Hawgood, J., Krysinska, K., De Leo, D. (2006) A study examining the feasibility of developing, piloting and evaluating a suicide prevention curriculum for undergraduate medical students. A report to the Commonwealth of Australia, Department of Health and Aging. Australian Institute for Suicide Research and Prevention, Brisbane. 
Hawgood, J.L., Krysinska, K.E., Ide, N., De Leo, D. (2008) Is suicide prevention properly taught in medical schools? Medical Teacher, 30: 287-295.

Hayes, R.P., Stoudemire, A.S., Kinlaw, K., Dell, M.L., Loomis, A. (1999). Changing attitude about end-of-life decisions making of medical students during third-year clinical clerkship. Psychosomatics, 40, 205-211.

Haverkate, I, van der Heide, A., Onwuteaka-Philipsen, B.D., van der Mass, P., van der Wal, G. (2001). Medical Journal of Australia, 175, 519-522.

Hendin, H., Klerman, G. (1993). Physician-assisted suicide: the dangerous of legalization. American Journal of Psychiatry, 150, 143-145.

Herron, J., Ticehurst, H., Appleby, L., Perry, A., Cordingley, L. (2001). Attitudes towards suicide in front-line health staff. Suicide and Life-Threatening Behavior, 31, 342-347.

Khuse, H., Singer, P., Baume, P., Clark, M and Rickard, M. (1997). End-of-life decisions in Australian medical practice. Medical Journal of Australia, 166, 191-196.

Kelly, B., Burnett, P., Badger, S., Pelusi, D., Varghese, F.T., Robertson, M. (2003). Doctors and their patients: a contest for understanding the wish to hasten death. Psycho-Oncology, 12, 375-384.

Kelly, B.J., Varghese, F.T., Pelusi, D. (2003). Countertransference and ethics: A perspective on clinical dilemmas in end-of-life decisions. Palliative and Supportive Care, 1, 367-375.

Kelly, J.B., Pelusi, D., Burnett, P.L., Varghese. (2004). The prevalence of psychiatric disorder and the wish to hasten death among terminally ill cancer patients. Palliative Support, 2, 163-169.

Kissane, D.W., Street, A., Nitschke, P. (1998). Seven deaths in Darwin: case studies under the Rights of the Terminally IlL Act, Northern Territory, Australia. Lancet, 352, 1097-1102.

Lavery, J.V., Boyle, J., Dickens, B.M., Maclean, H., Singer, P.A. (2001). Origins of the desire for euthanasia and assisted suicide in people with HIV-1 or AIDS: a qualitative study. Lancet, 358, 362-367.

Luoma, J.B., Martin, C.E., Pearson, J.L. (2002). Contact with mental health and primary care providers before suicide: A review of the evidence. American Journal of Psychiatry, 159, 909-916.

Mak, Y., Elwyn. G., (2005). Voice of the terminally ill: uncovering the meaning of desire for euthanasia. Palliative Medicine, 19, 343-350.

Marcoux, I., Onwuteaka-Philipsen, B.D., Jansen-ven der Weide, M.C., van der Wal, G. (2005). Withdrawing an explicit request for euthanasia or physician-assisted 
suicide: a retrospective study on the influence of mental health status and other patient characteristics. Psychological Medicine, 35, 1265-1274.

Marquet, R.L., Bartelds, A.I., Kerkhof, A.J., Schellevis, F.G., van der Zee, J. (2005). The epidemiology of suicide and attempted suicide in Dutch general practice 19832003. BMC Family Practice, 4, 45-52.

Netherlands Institute for Health Services Research (2003). Palliative care for terminally ill patients in the Netherlands: Dutch Government Policy. International publication series health, welfare and support No 16. The Hague, the Netherlands.

Onwuteaka-Philpsen, B.D., Fisher, S.,Cartwright, C., Delien, L., Miccinesi, G., Norup, M., Nilstun, T., van der Heide, A., van der, Wal. (2006). End-of-life decision making in Europe and Australia. Archives of Internal Medicine, 166, 921-929.

Onwuteaka-Philipsen, B.D., van der Heide, A., Koper, D., Keiji-Deerenberg, I., Rietjens, J.A.C., Rurup, M.L., Vrakking, A.M., Georges, J.J., Muller, M.T., van der Wal, G., van der Mass, P.J. (2003). Euthanasia and other end-of-life decisions in the Netherlands in 1990, 1995, and 2001. Lancet, 362, 395-399.

Oregon Department of Human Service (ODHS). (2006). Eighth annual report on Oregon's Death with Dignity Act. Seattle, Oregon, US.

Rapport, W., Witzke, D. (1993). Education about death and dying during the clinical years of medical school. Surgery, 112, 163-165.

Raue, P.J., Meyers, B.S., Rowe, J.L., Heo, M., Bruce, M. (2007). Suicidal ideation among elderly homecare patients. International Journal of Geriatric Psychiatry, 22, 32-37.

Rurup, M.L., Onwuteaka-Philpsen, B.D., Jansen-van der Weide, M.C., van der Wal, G. (2005). When being, tired of living' plays an important role in a request for euthanasia or physician-assisted suicide: patient characteristics and the physician's decision. Health Policy, 74, 157-166.

Schwartz, C.E., Clive, D.M., Mazor, K.M., Ma, Y., Reed, G., Clay, M. (2005. Detecting attitudinal changes about death and dying as a result of end-of-life care curricula for medical undergraduates. Journal of Palliative Medicine, 8, 975-985.

Scoullar, K.M., Smith, D.I. (2002). Prevention of youth suicide: How well informed are the potential gatekeepers of adolescent in distress? Suicide and Life-Threatening Behavior, 32, 67-80.

Stevens, K.R. (2006). Emotional and psychological effects of physician-assisted suicide and euthanasia on participating physicians. Law \& medicine, 21, 187-200.

Sullivan, A.M., Lakoma, M.D., Block, S.D. (2003). The status of medical education in end-of-life care: A National Report. Journal of General Internal Medicine, 18, 685695. 
Tieran, E., Casey, P., O’Boyle, C., Birkbeck, G., Mangan, M., O’Siorain, L., Kearney, M. (2002). Relationship between desire for early death, depressive symptoms and antidepressant prescribing in terminally ill patients with cancer. Journal of the Royal Society of Medicine, 95, 386-390. 
Table 1. Participants' composition: gender and mean age of students by year

\begin{tabular}{|l|c|c|c|c|c|c|c|}
\hline $\begin{array}{l}\text { Undergraduate } \\
\text { year level }\end{array}$ & \multicolumn{2}{|c|}{ Males } & \multicolumn{2}{c|}{ Females } & \multicolumn{2}{c|}{$\begin{array}{c}\text { Total students } \\
\text { Response Rate (\%) }\end{array}$} & $\begin{array}{c}\text { Mean } \\
\text { Age }\end{array}$ \\
\hline First year & 74 & $44 \%$ & 95 & $56 \%$ & 169 & $73 \%$ & 25.5 \\
\hline Second year & 68 & $45 \%$ & 82 & $55 \%$ & 150 & $86 \%$ & 25.47 \\
\hline Third year & 8 & $40 \%$ & 12 & $60 \%$ & 20 & $80 \%$ & 27.5 \\
\hline Fourth year & 16 & $46 \%$ & 18 & $54 \%$ & 34 & $85 \%$ & 28.41 \\
\hline TOTAL & $\underline{166}$ & - & $\underline{207}$ & - & $\underline{373}$ & - & - \\
\hline
\end{tabular}

Table 2. Mean ratings of students' attitude towards suicide prevention

\begin{tabular}{|l|c|c|}
\hline \multicolumn{1}{|c|}{ Items/ Number of total responses } & Mean & SD \\
\hline I resent being asked to do more about suicide (n=365) & $1.81^{*}$ & .795 \\
\hline Suicide prevention is not my responsibility (n=365) & $1.72^{*}$ & .712 \\
\hline $\begin{array}{l}\text { Making more funds available to the appropriate health services would } \\
\text { make no difference to the suicide rate (n=365) }\end{array}$ & $2.23^{*}$ & .891 \\
\hline $\begin{array}{l}\text { Working with suicidal patients is not rewarding } \\
\text { (n=364) }\end{array}$ & 2.70 & .668 \\
\hline $\begin{array}{l}\text { If people are serious about committing suicide they don't tell anyone } \\
\text { (n=365) }\end{array}$ & $2.51^{*}$ & 1.013 \\
\hline $\begin{array}{l}\text { I feel defensive when people offer advice about suicide prevention } \\
\text { (n=364) }\end{array}$ & $2.16^{*}$ & .836 \\
\hline $\begin{array}{l}\text { It is easy for people not involved in clinical practice to make judgement } \\
\text { about suicide prevention (n=364) }\end{array}$ & 3.57 & .828 \\
\hline $\begin{array}{l}\text { If a person survives a suicide attempt, then this was a ploy of attention } \\
\text { (n=364) }\end{array}$ & $2.12^{*}$ & .918 \\
\hline People have the right to take their own life (n=360) & 2.92 & 1.108 \\
\hline $\begin{array}{l}\text { Since unemployment and poverty are the main causes of suicide, there is } \\
\text { little that an individual can do to prevent it (n=364) }\end{array}$ & $1.76^{*}$ & .668 \\
\hline I don't feel comfortable assessing someone for suicide risk (n=363) & $2.61 *$ & 1.006 \\
\hline $\begin{array}{l}\text { Suicide prevention measures are a drain on resources, which would be } \\
\text { more useful elsewhere (n=364) }\end{array}$ & $1.88^{*}$ & .773 \\
\hline There is no way of knowing who is going to commit suicide(n=364) & $2.20^{*}$ & .858 \\
\hline
\end{tabular}

*More than $60 \%$ of the student participants 'strongly disagree' or 'disagree' with the statements.

Lower scores indicate a positive attitude regarding the statement. 
Figure 1. Students' perceptions on euthanasia education

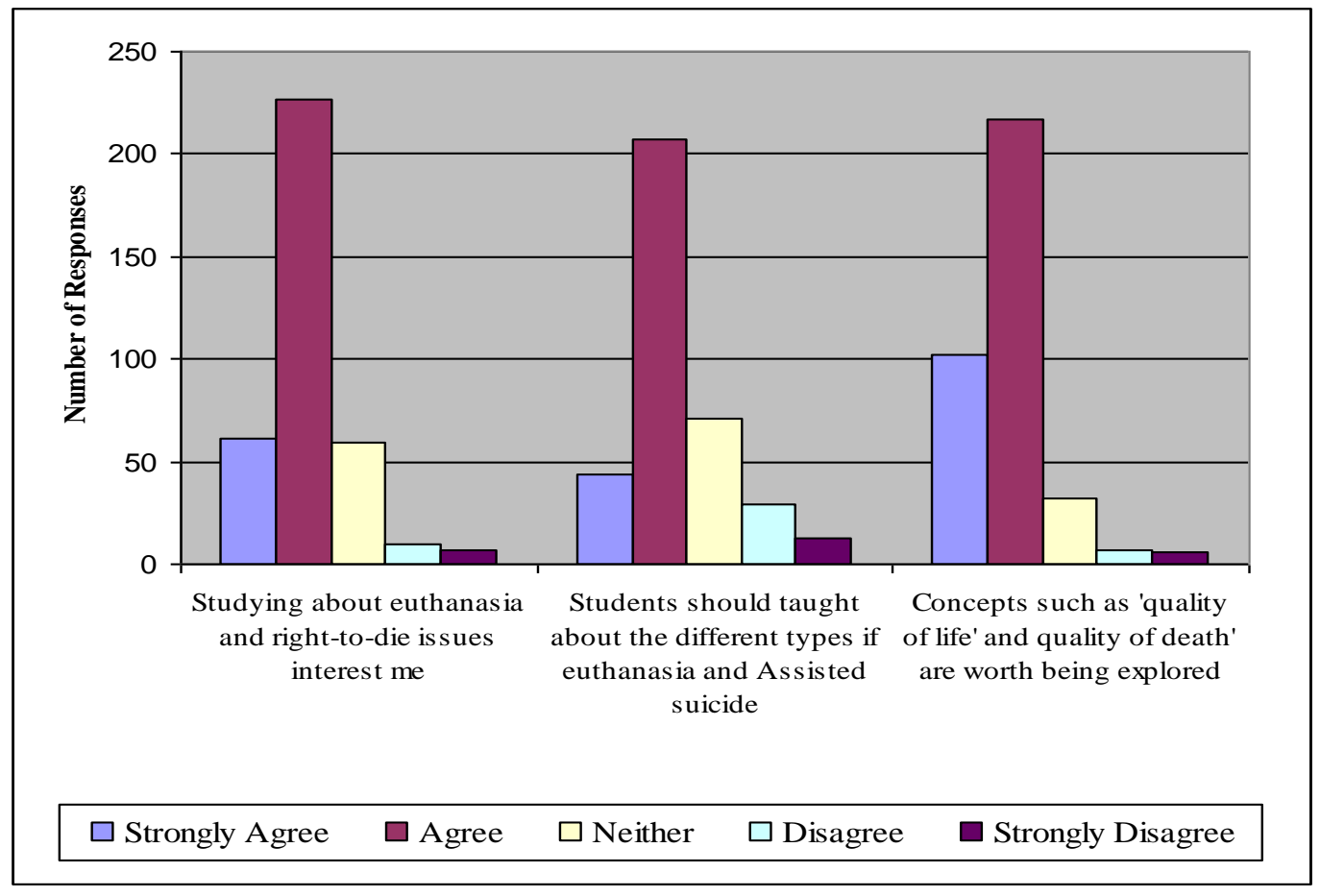

Figure 2. Students' perceptions on physicians' involvement in end-of-life issues

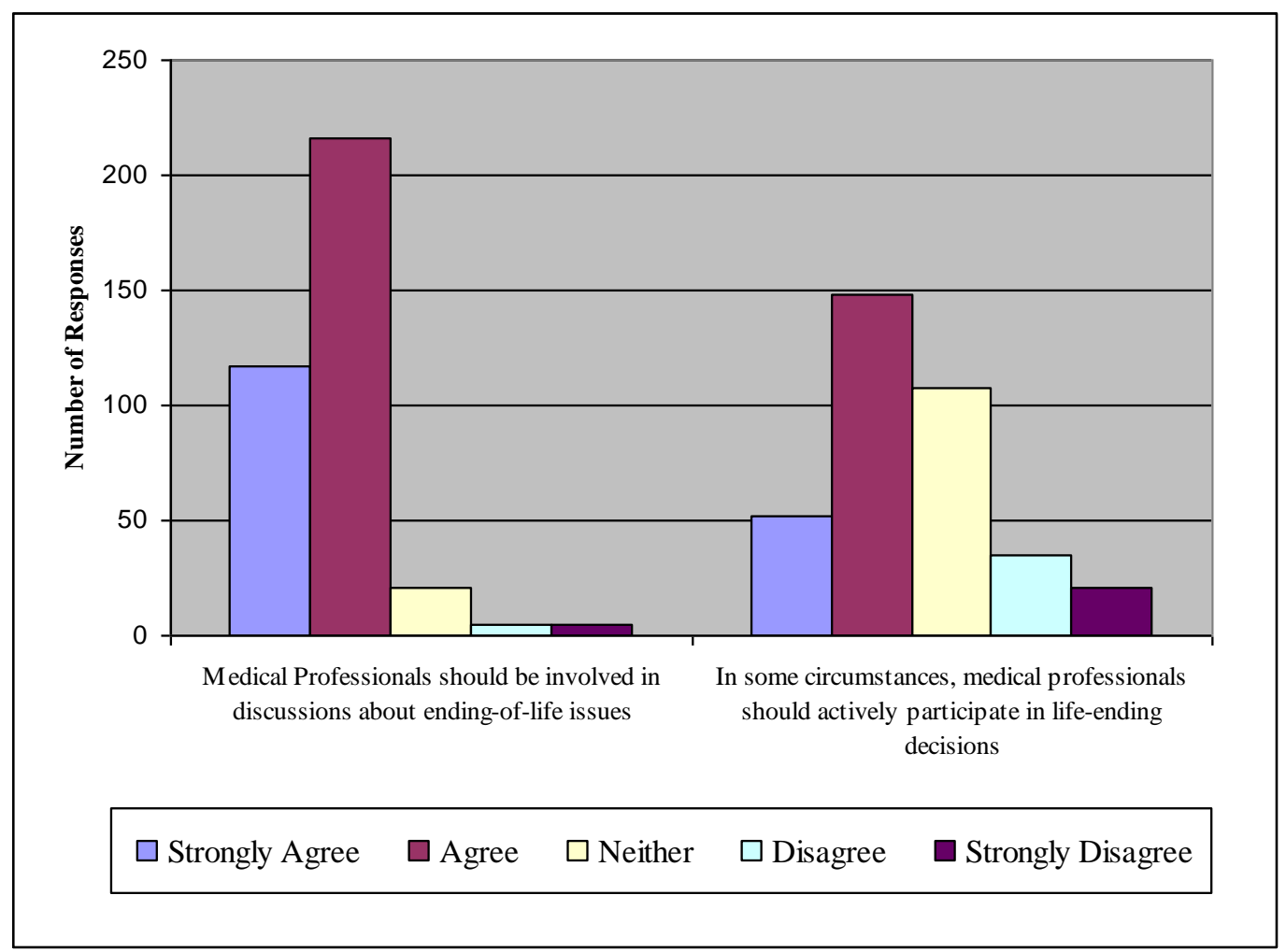


Figure 3. Preferred learning outcomes of Suicide Prevention education

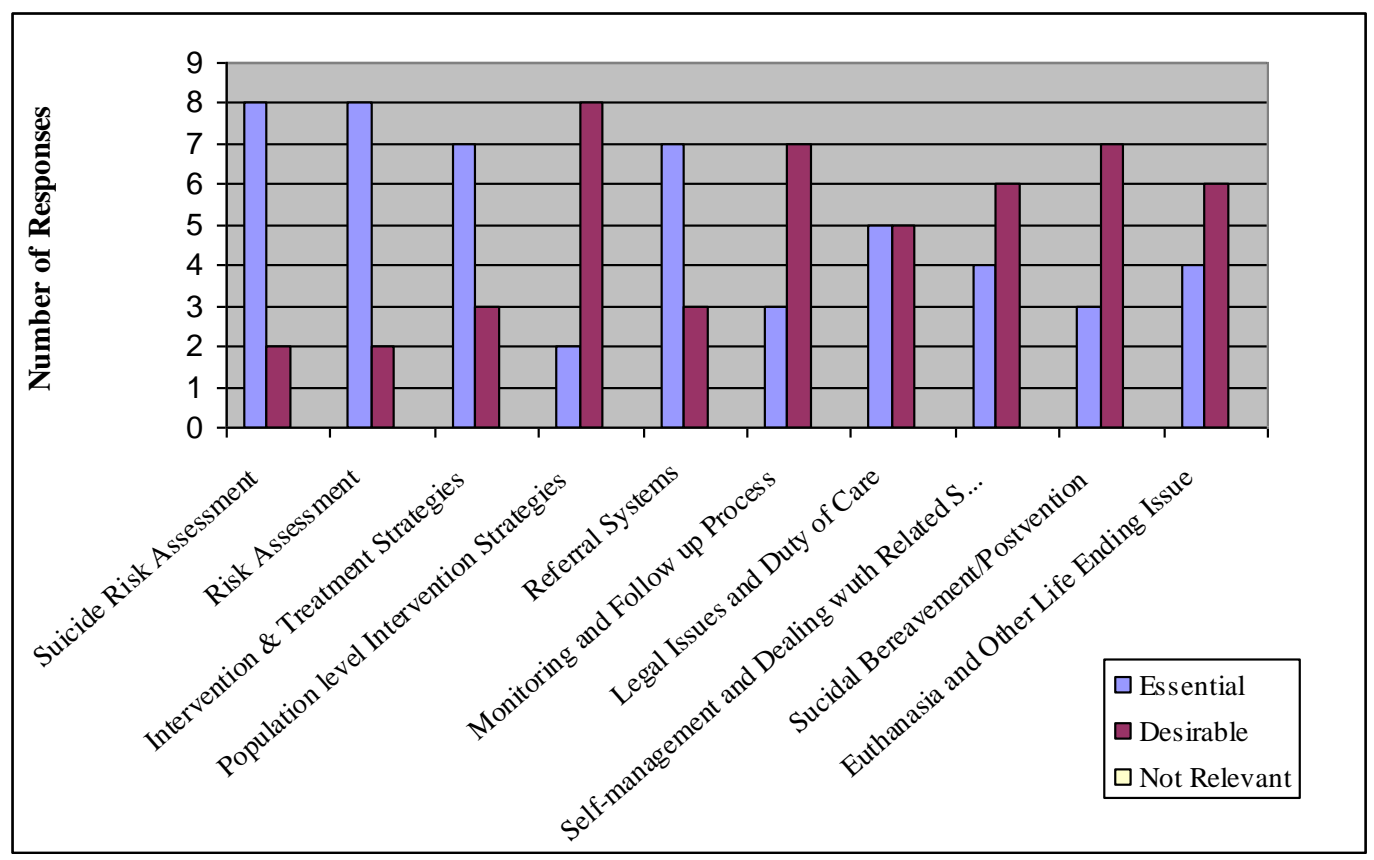

